\title{
Partnering for economic development: How town-gown relations impact local economic development in small and medium cities
}

Jennifer Massey, Sean Field, and Yolande Chan

Queen's University

\begin{abstract}
Universities play an increasingly prominent role in shaping regional, social, and economic development. In Canada, however, spatial, economic, and social differences between universities and their host communities continue to challenge positive town-gown relationships and undermine the benefits associated with high concentrations of prospective young, "creative" graduates. The purpose of this article is to identify the factors that lead to positive towngown relations and, subsequently, encourage graduate retention. Through this research, university and town administrators were found to play a key role in establishing a positive relationship between students and community members. Local employment opportunities were also found to help students build an experiential relationship with their localities and make them more likely to settle there after graduation.
\end{abstract}

\section{Résumé}

Les universités jouent un rôle toujours plus important en ce qui concerne l'expansion régionale, sociale et économique. Au Canada cependant, les différences spatiales, économiques et sociales entre les universités et leurs collectivités d'accueil, constituent toujours un défi pour les rapports positifs entre les villes et leurs universitaires, en plus de miner les avantages liés aux fortes concentrations de jeunes diplômés « créatifs » potentiels. Le but de cet article est d'identifier les facteurs qui conduisent à des relations positives entre les villes et leurs universitaires et, conséquemment, encouragent la rétention 
des diplômés. Par cette étude, l'université et les administrateurs de ville ont joué un rôle essentiel dans l'établissement d'une relation positive entre les étudiants et les membres de la collectivité. En outre, il a été démontré que des possibilités d'emploi locales aidaient les étudiants à établir une relation expérimentale avec ces localités et les rendaient plus enclins à s'y établir une fois leur diplôme obtenu.

\section{Introduction}

Universities play an increasingly prominent role in shaping regional, social, and economic development. They are "pivotal component[s] of an underlying infrastructure for innovation on which the system of knowledge-based capitalism draws" (Florida \& Cohen, 1999, p. 604). Local intellectual and knowledge creation is of primary importance for regional economic development (Russo, van den Berg, \& Lavanga, 2007), and universities stimulate this development by providing local employment and also through the establishment of local knowledge networks and research and development strategies (Huggins \& Cooke, 1997; Huggins, Jones, \& Upton, 2008). The evolution of university-industry knowledge incubators are indicative of this process (Etzkowitz, 2002).

In Canada, universities play an increasingly central role in the economic development of mid-sized cities. With unprecedented leverage in both land and labour markets, urban and semi-urban universities have partnered with city councils to redraw local social and economic geographies. These partnerships are predominant in Ontario, where the consequences of global economic restructuring (e.g., the erosion of the manufacturing sector and the rise in service-based industries) are particularly apparent. Strategic town-gown partnerships, designed to support local economic development by enticing recent graduates to live and work in the locality, are now in place across the province.

For some communities, tumultuous relationships between the university administration and the surrounding community have been a barrier to the university-driven approach to economic growth and the universities' abilities to influence a community's economic geography (Massey \& Gouthro, 2011). In response to a growing awareness of the economic, social, and cultural benefits of harnessing a university's knowledge-based resources, Ontario communities have begun to address these historically strained towngown relations. Examples of partnerships developed in recent years include: (a) the strategic agreement between the London Municipal Council and the University of Western Ontario, whereby the Mayor of London now serves on the board of governors for the university; (b) the Town and Gown Committee of the City of Waterloo, which is comprised of representatives from the cities of Waterloo and Kitchener, the two local universities - the University of Waterloo and Wilfred Laurier University - and the satellite campus of Conestoga College; (c) the Town and Gown Committee of the City of Windsor, with representatives from the University of Windsor and St. Clair College; (d) the Town and Gown Advisory Committee of the City of Brantford, with representatives from Wilfred Laurier University at Brantford, Nipissing University, and Mohawk College; and (e) the 2010 town-gown strategic plan developed between the City of Kingston, the Kingston Economic Development Corporation (KEDCO), and Queen's University.

Town-gown relations are a pressing priority for city governments and university administrations. For city governments, universities hold a key to economic development 
(Mullin \& Kotval, 2012). For universities, partnerships with the local community are politically important. In Ontario, the call for universities to demonstrate their "regional relevance," and discussion about the benefits of greater differentiation within Ontario's university sector (Weingarten \& Deller, 2010), have pressured institutions to demonstrate how they support the local community and economy. One of the most common measures of this impact is the proportion of university students who remain in the local area after graduation. In the new knowledge-based economy, or what Florida (2002) termed the "creative economy," university graduates are the cornerstone of local economic development strategies.

Across Ontario, mid-sized regional towns and cities are increasingly implementing strategic plans that seek specifically to attract and retain university graduates. According to Florida (2002), the driving force of growth and development in cities, regions, and nations around the world is human creativity. He argued that rather than jobs forcing people to relocate, "companies cluster in order to draw from the concentrations of talented people" (Florida, 2005, p. 29). Cities with a high density of creative workers, he asserted, have a competitive advantage in the new knowledge-based economy. Following Florida's argument, several mid-sized cities across Ontario, including London, Kingston, and Waterloo, have implemented economic development strategies with the specific intention of attracting and retaining university graduates. Indeed, the economic development plans for all three cities identify the nexus of competitive advantage as creative industries and specifically seek to generate, retain, and attract members of the "creative class." According to Florida, creative young workers move to cities with strong labour markets and vibrant neighbourhoods, where the character and street life are culturally distinctive and novel (Florida, 2002; 2005). They are attracted to localities with an abundance of cultural amenities and lifestyle options. This includes interesting cafés and restaurants, and thriving music, art, literature, and design opportunities (Knox, 2005). Florida (2005) suggested that unleashing people's creative potential involves cultivating a culture of openness, tolerance, and diversity. He claimed that the creation of a distinctive social-cultural milieu aids in the rapid transmission of knowledge and ideas, providing cities with a competitive advantage. Across Canada, large and medium cities promote lifestyle preferences that appeal to individuals with intellectual and creative abilities.

Regional cities, which struggle to compete with national and global cities for investment, have spent heavily on improving amenities, such as recreational facilities and cultural attractions, in an effort to draw creative workers (Mullin \& Kotval, 2004). In this process, cultivation of local cultural and creative industries, including the performing arts, music, broadcasting, and film industries, became necessary for municipal wealth accumulation (Montgomery, 2005). While it is well established that cultural and local amenities are considered essential components of attracting young talent and creative industries, the importance of these amenities to retaining talent in university communities is under-explored (Van Winden, Van den Berg, \& Pol, 2007).

This article uses Kingston, Ontario as an illustrative case study to examine factors that entice graduate retention in medium-sized, university cities. The findings suggest town-gown relations are pivotal in students' perceptions of the host community as a place to live and work post graduation. Negative town-gown relations serve as a significant "push-factor" encouraging students to leave when they have completed their university 
studies. Positive town-gown relations emerge as a "pull-factor" enticing students to stay. We argue that co-curricular initiatives can play an important role in supporting positive town-gown relations and significantly contribute to strategic university-city partnerships. Leadership development programs; experiential, community, and work-integrated learning; and volunteer programs are a few of the ways universities can establish the student-community links found to be essential for positive town-gown relations. By working with local governments, universities and colleges can contribute to the growth and development of local economies by retaining large pools of knowledgeable, creative workers within a particular locality. College town officials have reason to believe that universities are not only a vital source of local jobs, but also an untapped source of educated young workers who can contribute innovative ideas to the local economy. For this to be achieved, cities must develop positive relationships between students and their host communities.

The empirical data presented were collected from students studying at Queen's University - a highly selective, research-intensive university - located in the mid-sized city of Kingston in eastern Ontario (see Fig. 1). The findings of this study have implications for university administrators, economic developers, and urban planners across Canada.

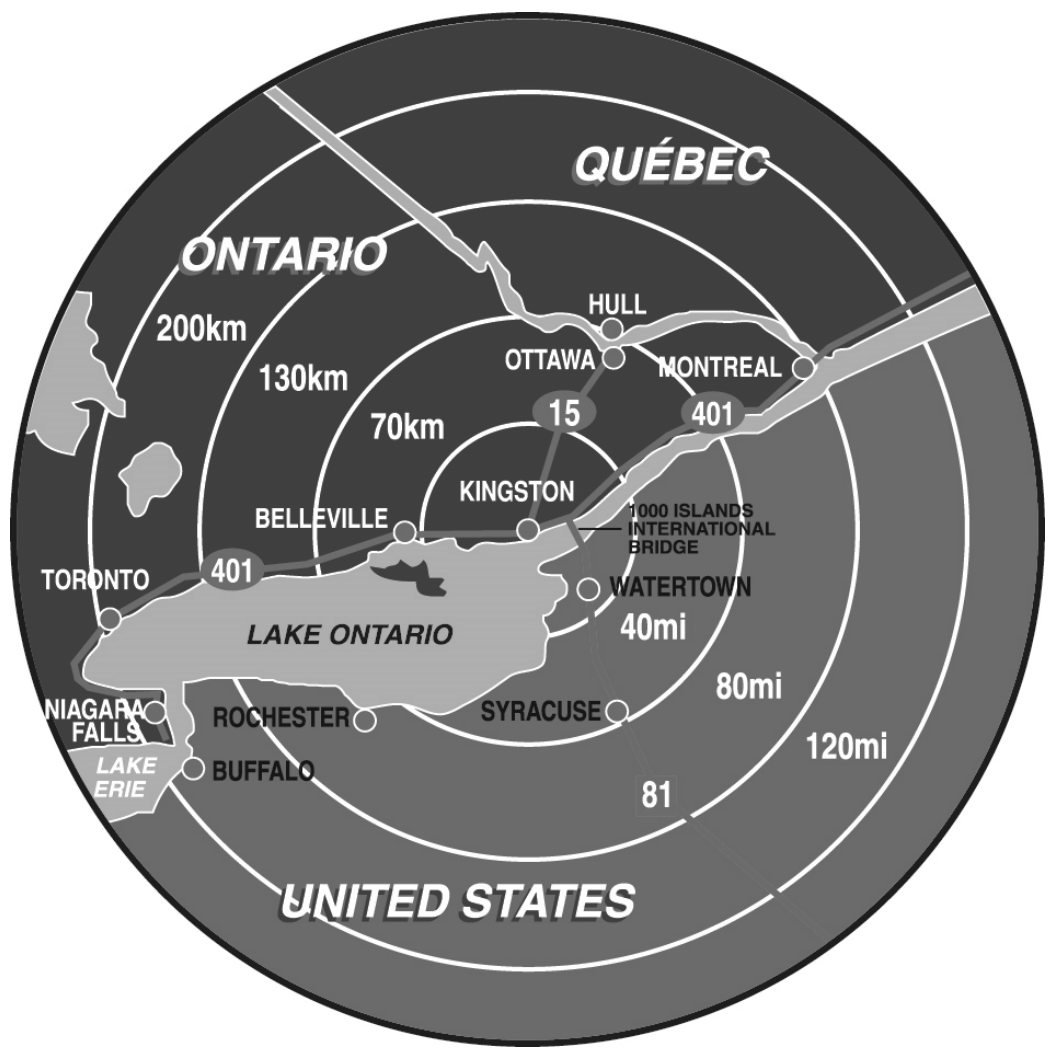

Figure 1. Location map, Kingston, Ontario

\section{Town-Gown Relations: The City of Kingston and Queen's University}

In addition to changing spatial and economic relations, tumultuous town-gown relations have also been linked to "studentification," whereby an increasing number of students move into traditionally non-student neighbourhoods (Sharma \& Young, 2008; Smith, 2005). This leads to "profound cultural, social, physical and economic transfor- 
mations" (Universities UK, 2006, p. 8) because the universities and colleges are unable to accommodate the growing influx of students within traditional on-campus housing (Sharma \& Young, 2008). Through the process of studentification, the concentration of students and shared housing in certain parts of the city has contributed to the spatial separation and centralization of student amenities and lifestyle activities (Fox, 2008). These conditions have intensified the concentration of poor housing and noise disturbances, creating an unwelcoming environment for the residents inhabiting adjacent areas (Sharma \& Young, 2008). In cities across Canada, such as Guelph, Waterloo, and Calgary, student housing supply and demand, community safety, and student behaviour and property standards (including poor maintenance of front lawns, limited garbage and recycling disposal, and noise pollution) have been identified as challenges to improving town-gown planning efforts (Sharma \& Young, 2008). Some communities have introduced enhanced police services, property maintenance standards, and tenancy policies to protect the physical and social environment of their neighbourhoods. Questions concerning who should pay for properly maintained student housing districts have also caused controversy between university administrators and city officials (Oddie et al., 2009). In Waterloo, the municipal government has undertaken proactive parking, noise, and property standards bylaw enforcement and has increased police patrols, in an effort to manage student behaviour and poor property maintenance by landlords. The tendency to portray students as a subgroup of the community has caused some students to feel marginalized and excluded from the local area and therefore less committed to maintaining the quality of the local environment (Sharma \& Young, 2008). These reinforcing relationships have intensified the social divisions between "town" and "gown," minimizing a sense of community cohesion and fuelling resentful attitudes between students, landlords, local residents, and civic officials.

In Kingston, town-gown studentification tensions are partly a consequence of the development of the student "ghetto" - the name associated with the streets surrounding the campus. In turn, the "ghetto" has become synonymous with noisy student parties and behaviour. This is exemplified for many locals by the well-publicized annual (and unsanctioned) Aberdeen Street party. The party, associated with Queen's University's Fall Homecoming celebration, drew approximately 8,000 people in 2007 (an increase from 5,000 people in 2005). Kingston police issued numerous fines, made arrests, and laid charges. In 2008, Queen's University issued a two-year moratorium on Homecoming and subsequently extended the ban for an additional three years.

\section{Method and Methodology}

Florida's (2004) "creative class" thesis framed the investigation that built upon previous research into factors impacting the likelihood of a student remaining in a university town post graduation (Massey, Chan, Field, \& Smith, 2011). Massey et al. (2011a) found that students' sense of place affected their intention to seek graduate employment locally, and that a sense of place was constructed from their feelings of satisfaction with a community and of belonging. In this paper, we build upon these findings to explore how students' perceptions and experiences affect their sense of place. We argue that students' sense of community satisfaction reflects their broader feelings about a locality, whereas their sense of belonging is constructed from the community interactions and communitybased experiences they have during their time in college (see Figure 2). 


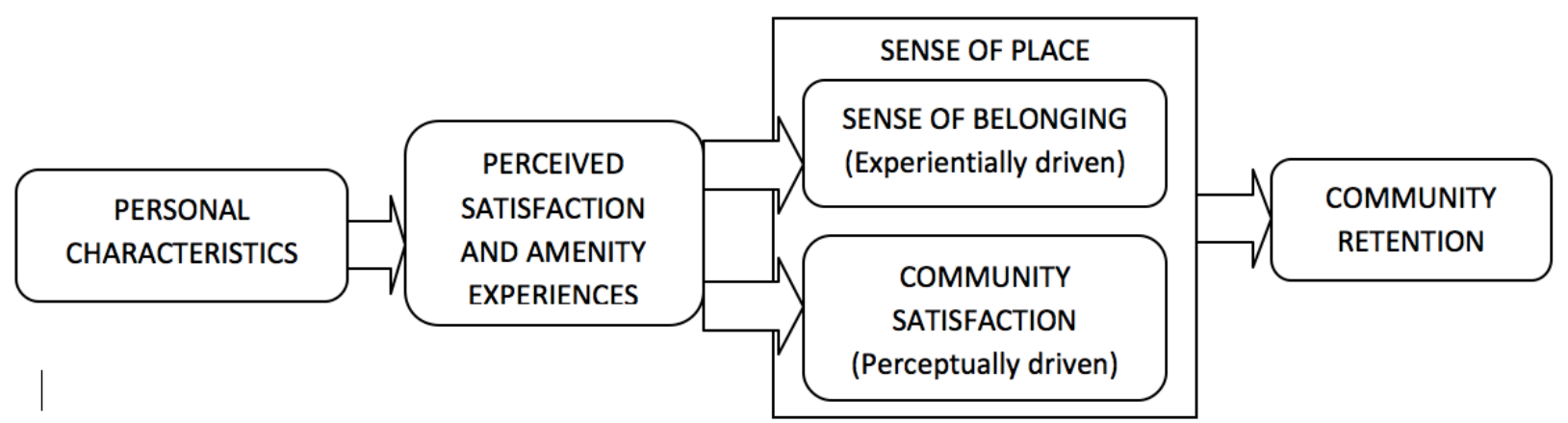

Figure 2. Creative community retention theoretical framework

A mixed-methods approach was adopted for this study because the research questions were broad, complex, and could not be answered sufficiently by utilizing an exclusively quantitative or qualitative research design. Data collection began with a series of focus groups, held with 28 third- and fourth-year undergraduates and graduate students. The information generated was used to design a web-based survey that was administered to a random sample of 2,500 third-year, fourth-year, and graduate students. ${ }^{1}$ The survey items included Likert-scale and open-ended qualitative questions. Nine hundred and fourteen students participated in the survey, constituting a 37 percent response rate. Overall, the survey drew on a diverse group of students, although this diversity was not evenly distributed (see, for example, Table 1).

Table 1

Participant Characteristics

\begin{tabular}{lr}
\hline Gender & \\
\hline Men & 206 \\
Women & 523 \\
\hline Disability & \\
\hline Yes & 841 \\
No & 57 \\
\hline Household Status & \\
\hline No Children Living & \\
$\quad$ with Me & 681 \\
1 Child at Home & 11 \\
2 Children at Home & 6 \\
3 or More Children & \\
$\quad$ at Home & 4 \\
Other & 17 \\
\hline Relationship Status & \\
\hline Single & 330 \\
Dating & \\
Married/Common- & \\
$\quad$ Law & \\
Separated & 57 \\
Divorced & 1 \\
Widowed & \\
\hline &
\end{tabular}

\begin{tabular}{lr}
\hline Sexual Orientation & \\
\hline Heterosexual & 652 \\
Homosexual & 19 \\
Bisexual & 17 \\
Other & 3 \\
\hline Citizenship & 736 \\
\hline Canadian Citizen & 21 \\
Permanent Resident & 0 \\
Other & \\
\hline College & 101 \\
\hline Applied Science & 451 \\
Arts \& Science & 29 \\
Business & 24 \\
Law & 26 \\
Medicine \& Health & 86 \\
Theology & 82 \\
Education &
\end{tabular}

\begin{tabular}{lr}
\hline Race & \\
\hline Black & 3 \\
Chinese & 68 \\
Filipino & 2 \\
Japanese & 0 \\
Korean & 6
\end{tabular}

South Asian or East Indian

29

South East Asian

Native Canadian

Arab, West Asian, or North African

Latin American

11

Mixed Origin

1

White

Other

\section{3}

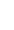

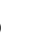


Quantitative data was analyzed using propensity score matching (PSM). PSM was employed to examine the treatment effect of several factors that, according to Florida's (2002) thesis, influenced an individual's perceived sense of belonging and satisfaction in Kingston. PSM has the advantage of overcoming problems associated with other comparative multivariate methods, such as ANOVA, by only comparing participants who are assessed to be characteristically similar. In PSM, participants in the control and treatment groups are assessed to have a similar propensity for being exposed to the treatment variables under scrutiny (Becker \& Ichino, 2002; Rosenbaum \& Rubin, 1983). This analytical technique enabled an exploration of factors that affected an individual's sense of place, and the subsequent likelihood of postgraduate retention, while strictly controlling for a parsimonious set of underlying demographic characteristics (as shown in Figure 2).

Propensity scores were calculated in STATA using a probit model. Only participants sharing a common region of support were included in the analyses, and the set of demographic matching covariates included in the estimation were chosen based on the availability of demographic and other relevant data. Participants were matched according to gender, relationship status, age, race, citizenship, number of children, and whether they identified as having a disability. The nearest neighbour method was used to compare participants, and matching was conducted with replacement ${ }^{2}$ (for a more detailed explanation, see, for example: Becker \& Ichino, 2002; Caliendo \& Kopeinig, 2008; Rosenbaum \& Rubin, 1983).

Overall, 40 PSM analyses were conducted. These results are summarized in Table 2. The matching criteria used for each analysis were identical. Where binomial treatment variables were created from questions that asked participants to give their answer according to a scale (for example, ranking their satisfaction from one to five), only positive (i.e., "satisfied" or "good") or strongly positive (i.e., "very satisfied" or "very good") responses were coded as positive (1). All other responses were coded as non-positive (0). The two outcome variables examined in the analyses were constructed from scaled responses and are binomially distributed (i.e., o or 1). Consequently, the average treatment effect on the treated (ATT) reported in Table 2 should instead be interpreted as probabilities (Becker \& Caliendo, 2007; Li, Racine, \& Wooldridge, 2008).

Qualitative responses to 11 of the survey questions were used for content analysis. These questions asked students to elaborate on the social, economic, and cultural aspects of Kingston. Content analysis examined the discourses regarding lifestyle preferences and perceptions of Kingston embedded participants' responses. Two content areas (Baxter, 1991) were examined: (1) attitudes about Kingston and (2) factors influencing participants' postgraduation employment search. The data contained in each of the units were then divided into meaning units (Baxter, 1991), condensed (Coffey \& Atkinson, 1996), and coded. Finally, data were sorted into 10 categories, 21 subcategories, and three overarching themes.

\section{Results}

The results of the quantitative analysis support previous studies indicating that community engagement, particularly through the employment sector, is a critical factor in postgraduate retention in small and medium cities (Massey et al., 2011a). The results in Table 2 indicate that students who held summer employment were more likely than 
those who had never done so to feel a sense of belonging in the city. Interestingly, participants who felt that the city was a good place for entrepreneurs also reported feeling a sense of belonging in Kingston, suggesting that this may be driven by direct or indirect experience in entrepreneurship. Participants who were satisfied with Kingston's employment prospects and socioeconomic conditions, by contrast, reported feeling satisfied with the community, as well as reporting a stronger sense of belonging than those who were not satisfied with Kingston's employment prospects. These results suggest while employment experiences positively affect students' experiential sense of place, student satisfaction with perceived employment prospects and socioeconomic conditions are also important to this construction. For student affairs professionals and town administrators, these results indicate that both student employment experiences and students' broader local economic and socioeconomic perceptions are important for their constructed sense of place and, consequently, positive town-gown relations. Student affairs professionals may positively influence the student aspect of town-gown relations and the likelihood of subsequent postgraduate retention by connecting students to local employers. Programming that encourages students to seek meaningful local employment and fosters positive perceptions of economic and socioeconomic conditions amongst students will improve student understanding of and relationships with the local community.

Participants who reported being uninterested in obtaining summer employment in the local area were significantly more likely to report feeling no sense of belonging to the community and were more likely to report being dissatisfied with the community overall. These results suggest disengagement from the local job market has both an experiential and a perceptive impact on a student's sense of place. If students identify the local area as having few employment prospects (whether their perception is accurate or not), they are less likely to seek employment and internships placements with local businesses and organisations, which mitigates their experiential sense of belonging and significantly reduces their postgraduate retention.

Non-employment experiences were also found to be important to an individual's sense of belonging. Students who participated in local religious activities, for example, were more likely to report feeling a sense of belonging to the community. Local businesses and faith-based groups may be interested in these results because they suggest that local consumer and religious engagement may influence an individual's sense of belonging. Further research is needed, however, to accurately decipher the strength of these effects, the sensitivity of these effects to change, and whether particular forms of consumer and religious engagement are more important than others. For example, shopping at stores in the old downtown, rather than in modern shopping malls, may have a different effect and require further investigation.

The impact of student overall satisfaction with the shopping, entertainment, and home-to-work proximity aspects of Kingston had experiential and perceptual effects on students' sense of place. Those reporting being satisfied with the shopping, entertainment, and home-to-work proximity aspects were more likely to report feeling a sense of place and satisfaction in the community. Individuals who reported feeling satisfaction with Kingston's sustainability initiatives, its maintenance of road, lane, and path infrastructure, and its snow and garbage removal also reported feeling community satisfaction. These results suggest that while some factors influence experiential sense of place, others influence perceptual sense of place. 
Partnering for economic development / J. Massey, S. Field, \& Y. Chan 160

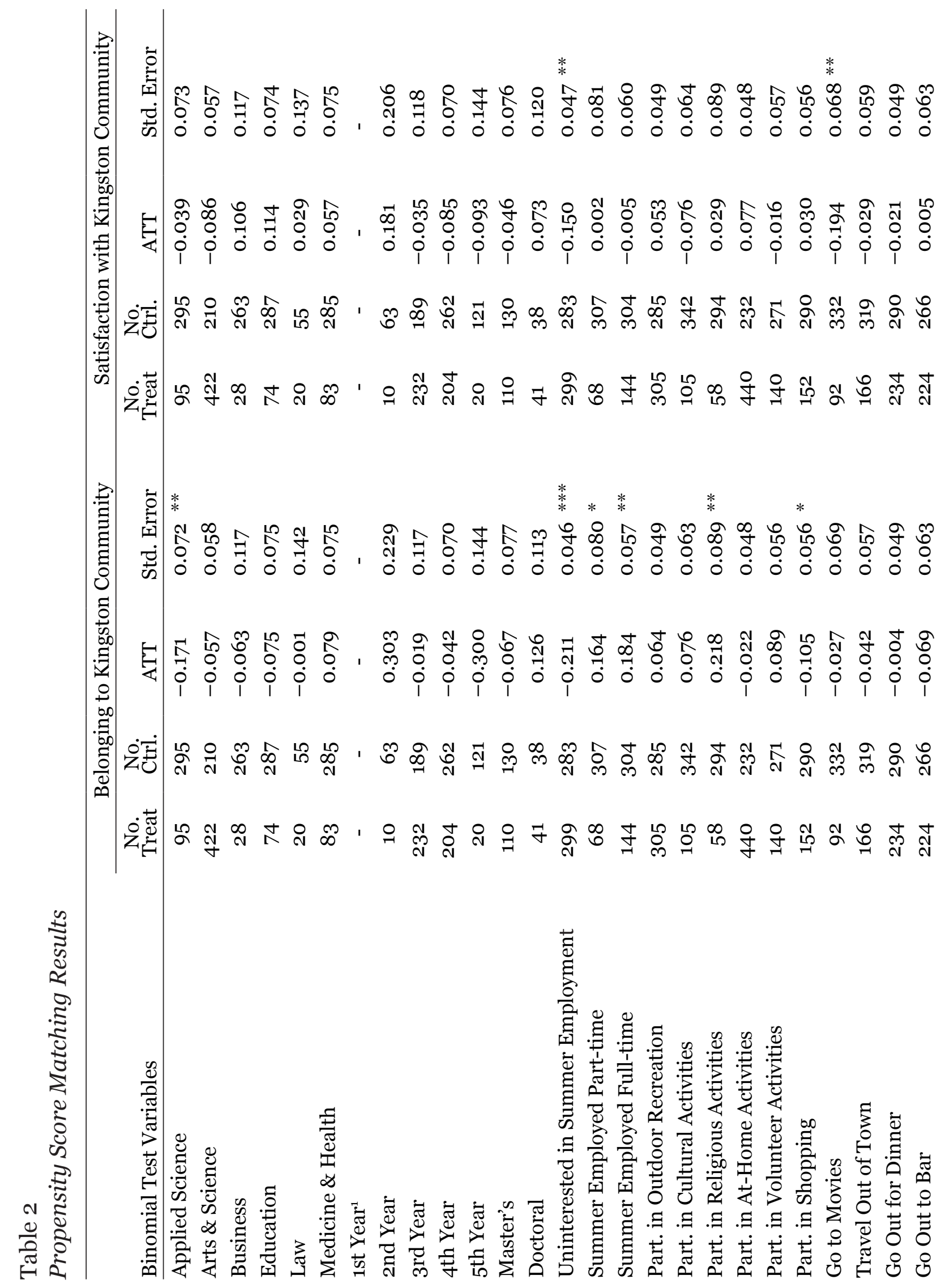




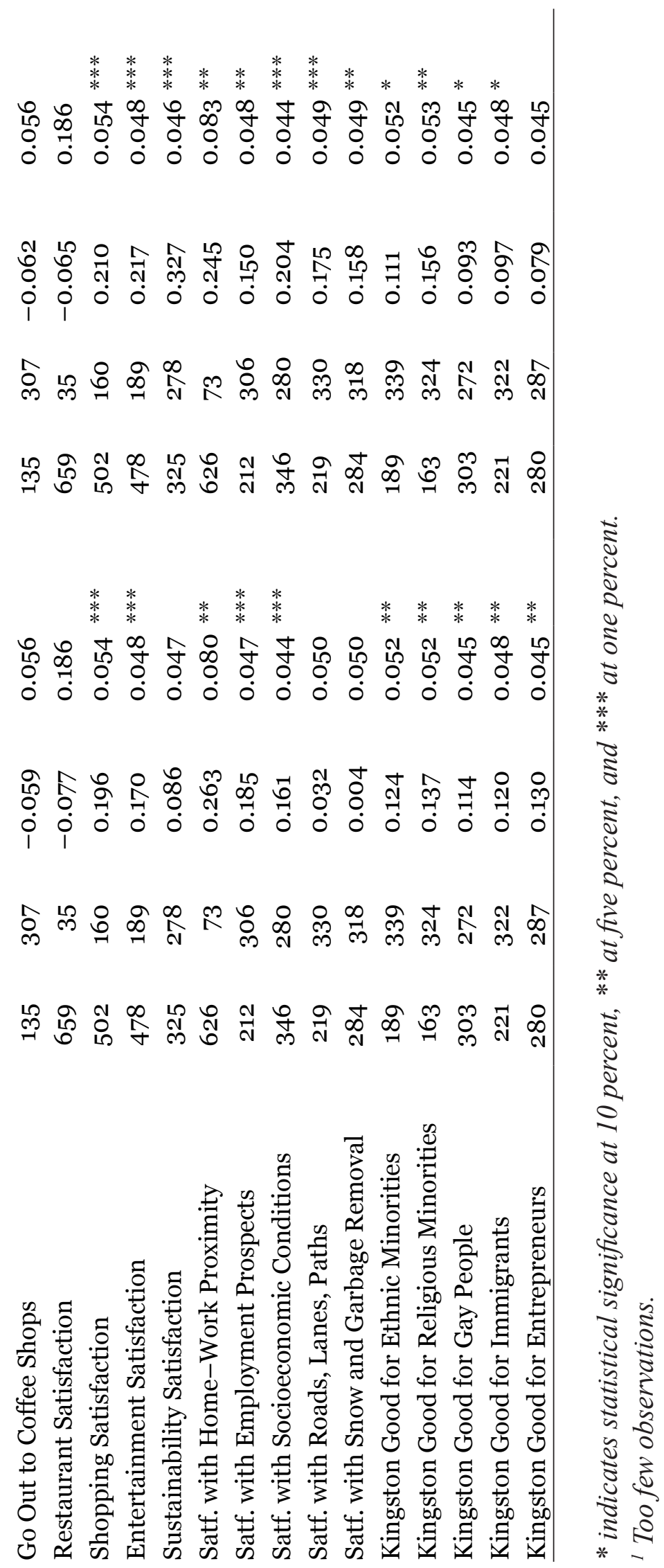


Other factors, by contrast, influence both experiential and perceptual sense of place. Overall satisfaction with the shopping, entertainment, and home-to-work proximity aspects of Kingston are a good instance of this dual effect. An individual's sense of place, for example, may be influenced by their perceived selection of shopping and entertainment amenities in Kingston and also by their experiences in these venues. Sustainabilityconscious individuals may garner satisfaction not only from knowing that the university, the downtown, and the "student ghetto" are situated in close proximity - making them very pedestrian and bike friendly - but also from the experience of walking to and from school (or downtown) every day. For student affairs professionals and town administrators, these dual sense of place factors may be key to attracting new students to the community and keeping them post graduation.

Those who reported that Kingston was a good community for ethnic minorities, religious minorities, new immigrants, and members of the queer community were also more likely than other participants to feel a sense of belonging and satisfaction. These results support Florida's (2004) assertion that cities more hospitable to marginalized groups are more attractive to prospective graduates, who increasingly value diversity. ${ }^{3}$ Increasing awareness of the importance of diversity to a community's vibrancy may explain, for example, why individuals who reported that Kingston is a good community for marginalized groups also reported being more satisfied with the community overall. Only six percent of the participants in our sample identified as LGBTQ, and only 24 percent identified as being members of an ethic minority. Unlike other covariates examined here, such as shopping, systemic marginalization is experienced by choice. These results should be interpreted critically as they may be driven by anecdotal or other experiences by individuals from non-marginalized groups and may not reflect the reality experienced by marginalized individuals. Student affairs professionals and town administrators should pay close attention to these results, however, because they suggest that individuals who value local diversity are likely to feel a stronger sense of place. For town administrators, this implies that actively fostering local diversity may be an important part of encouraging postgraduate retention. For student affairs professionals, these results stress the importance of diversity and highlight that local diversity may be important for fostering positive towngown relations.

The qualitative data obtained through the open-ended survey questions added depth to these findings. These results revealed that the (real or perceived) negative attitudes of Kingston residents toward Queens University students weakened students' sense of place and discouraged them from considering Kingston as their prospective postgraduate home. Many participants attributed their feelings of estrangement to encounters with residents in the community. One student said, for example:

I was born and raised in Kingston, and have been very active in the community my entire life (volunteering, local theatre, etc). Since coming to Queen's, I have faced prejudice most places I frequent in Kingston, from local businesses, to cab rides, to walking down the street. It is difficult to feel part of a community under these circumstances. (Female, Fourth Year, Arts \& Science)

One student elaborated on the impact of negative town-gown relations on the likelihood of settling in Kingston after graduation: 
To be honest, part of the lack of desirability to remain in Kingston after graduation stems from the inhospitable and often hostile attitude that some Kingston residents have towards Queen's students. Their perception of us as outsiders and a disturbance undermines our economic and community contributions to the city and makes us feel wholly unwelcome here. Very little of me desires to remain in a community that has been so hostile and derisive of my presence. (Female, Third Year, Arts \& Science)

In addition to feeling marginalized and excluded from the greater Kingston community, students expressed being unfamiliar with places off-campus, a factor that contributed to their feelings of isolation and disconnection from the city. For example, one student remarked, "[I] don't interact with very many members of the [community], am not familiar with any other parts of Kingston besides the 'Queen's area"' (Female, Third Year, Arts \& Science). Elaborating on the impact of the student village on town-gown relations, another student said, “Because I live in the 'Queen's Ghetto,' I feel that we have created our own 'bubble' and I do not feel immersed in the greater community" (Female, Third Year, Arts \& Science). Students described three different "communities" in Kingston: the Queen's academic community (consisting of undergraduate students, graduate students, student services, and faculty members), the surrounding student housing area, and the broader, non-Queen's Kingston community. Considering these attitudes, it is not surprising that of the 836 students who responded to the question "Do you consider yourself to be a member of the Kingston community?", 44 percent replied "no." Although more than half of students considered themselves part of the community, this did not translate into wanting to stay in Kingston after graduation. Almost 80 percent of those looking for post-graduation employment did not consider Kingston. Student experiences in Kingston and their understanding of residents' attitudes towards them evoked a desire to leave post-graduation.

Many students who participated in this study indicated a level of displeasure with the city council's perceptions and treatment of students. One, for example, said:

[I'm] extremely dissatisfied with the hostility of the Kingston municipal government and the local Press in their attitude and treatment of students. Focus on homecoming is ... totally disproportionate to the facts of the weekend. Only $30 \%$ of arrests were Queen's students, and yet the municipality has taken draconian steps to punish all Queen's students. (Male, Fourth Year, Arts \& Science)

Another asserted:

I am extremely dissatisfied with the way in which the City of Kingston ... and media are unable to fairly ... portray Queen's University students, particularly with the events of the Homecoming street party ... many sources have shown that the majority of Queen's students did not attend this party ... I feel as though this has created much resentment towards students that had no part in it. (Female, Fourth Year, Arts \& Science)

These comments suggest that students see the city council as prejudiced and disgruntled with their presence in Kingston, intensifying their feelings of exclusion. There is a danger that this prolonged and constant criticism will disaffect students and impede retention after graduation. 
Summer employment was an important factor in influencing students' perceptions of Kingston. Students who found summer employment locally were more likely to develop a favourable view of the city, supporting the results of the quantitative analysis and the findings of our previous work. One survey participant stated, for example, "During the summer I worked in Kingston so I feel much more attached to the city now" (Male, Third Year, Business). Considering that approximately 50 percent of students indicated that they have either looked for summer employment in the Kingston area or wish to, the potential exists to evoke a stronger sense of place attachment by offering students summer employment opportunities. The task is to ensure that students are recognized and appreciated as valuable assets to the local economy and welcomed into the city by residents, town council, and local businesses.

\section{Discussion and Recommendations}

The Kingston Economic Development Corporation (KEDCO) and the City of Kingston have emphasized their commitment to creating a sense of strong social cohesion in Kingston (Massey, Allen, and Shearer, 2011). The findings of the present study highlight the importance of addressing poor town-gown relations as part of this process. In particular, the authors' findings suggest that the student aspects of town-gown relations must be addressed through experiential and perceptual initiatives targeting meaningful student employment, community engagement, and student perceptions of community diversity and socioeconomic conditions. If Kingston and Queen's do not collaborate to counter long-term town-gown tensions, student-community relations will continue to deteriorate. This is counterproductive to the city's efforts to attract young creative graduates and knowledge-based professionals. Economic policy planners must prioritize efforts to improve student-community relationships if they wish to harness creative potential by retaining students as residents post graduation.

Kingston and other university communities can draw upon other examples to improve town-gown relations. In several cities, committees have been established to bring together city officials, postsecondary administrators, neighbourhood residents, students, landlords, and politicians to reduce town-gown conflict and negative town-gown perceptions. In Waterloo, for instance, the City of Waterloo and its universities (the University of Waterloo and Wilfred Laurier University) hosted a Town and Gown Symposium on student-community relations (Fox, 2008). The symposium identified a range of coordinated planning efforts that could be used to address issues which create tensions between students and community members, including sustainable housing, community policing, bylaw enforcement, and better communications with provincial ministries and agencies to improve housing and community safety (Fox, 2008). Similar events have now been held in the Ontario cities of Hamilton, Guelph, and St. Catharine's (Fox, 2008). Canadian postsecondary institutions are increasingly concerned with fostering positive town-gown relationships and supporting local economic development.

Fostering positive interactions between students and community members can be achieved on a more decentralized daily basis. For instance, while many Queen's students expressed feeling disconnected and unattached to Kingston, some indicated that their personal involvement with community groups, interaction with local residents in off-campus activities, and local employment made them feel more integrated with the community. By 
encouraging students to become actively involved in the community, university administrators can help foster positive town-gown relations, which will help boost the number of students who remain in the local community when they graduate.

On the resident side of town-gown relations, promoting the valuable contributions that universities make to their host city may improve student treatment in the community. Students indicated that the positive implications of their involvement remained unrecognized or underappreciated by the majority of residents, fuelling resentment and feelings of exclusion. Universities must draw attention to the valuable contributions their students make to their communities, not only by producing revenue and stimulating local economic growth, but also by offering a wide range of services and sociocultural benefits to local residents.

While university administrators must play an important role in town-gown relations, city council and municipal officials must also work to modify their policies and practices to create more welcoming and inclusive social spaces for students. Making students aware of the employment opportunities and community activities available to them may create conditions under which more graduates might remain as permanent residents. Although the results of the quantitative analysis do not speak to the issues of the "student ghetto" and studentification specifically, the dense spatial distribution of students in Kingston speaks strongly in the qualitative results and runs through the results. The data used for this study did not allow for an empirical spatial analysis to be conducted. However, it is clear that dense spatial distribution of students near campus is central to many town-gown tensions, because it reinforces the spatial divide and "us versus them" sentiments. This spatially reinforced outlook is likely one of the key dynamics influencing the results of the PSM analyses. While further analysis is needed to pinpoint these specific effects, student affairs and city officials may wish to consider strategies that encourage a less dense spatial distribution of students as part of a comprehensive town-gown plan.

Finally, while many of our findings focus on how university and town administrators can cultivate better town-gown relations and boost local economic prosperity, we also wish to underline the role that university students can play in improving their relationships with government officials and community residents. Students could take an active role in improving town-gown relations by reducing squalor and cutting down on the noise and drinking disturbances that foster resentment amongst non-student residents. University and town administrators could aid students in this process by providing information regarding the rules and expectations of living in the community, and by establishing student-led leadership programs that model positive town-gown relations.

\section{Conclusion}

The results from this quantitative and qualitative analysis indicate that in addition to offering a variety of amenities, small and medium cities in Canada hoping to retain their graduates need to provide meaningful employment opportunities to students before they graduate so that they can build on experiential relationships. A university-wide campaign by career services and the community to build engagement and retention amongst the student body may need to focus on students for whom few job prospects exist due to weak or non-existent local industries. These initiatives may include encouraging new firms in town, with the purpose of boosting student internships and graduate job opportunities, as 
well as establishing a framework to encourage industry-specific entrepreneurial activity. Administrators must make a concerted effort to identify the barriers to social integration and work collaboratively with regional players to improve town-gown relationships, while ensuring their students are respectful of the community. As a result, the host community will be guaranteed a valuable asset in the global competition for talent.

For administrators in co-curricular programs and community relations, this article makes several key contributions to the discussion about the role of student affairs in the Canadian and US creative economies. First, the findings presented support the findings of Massey et al. (2011a) regarding the importance of conceptualizing creative student retention in terms of a sense of belonging and satisfaction. Second, the results indicate that a community's openness to diversity is a factor affecting students' sense of belonging and satisfaction. Consequently, these results support Florida's (2004) assertion that diversity is an important factor for attracting young talent, even amongst those who do not identify as belonging to marginalized communities. The third contribution of this article is to build upon previous work by using propensity score matching to parse out what factors influence an individual's sense of place. While the results of the PSM analyses differ somewhat from the results of previous work, they coincide with findings overall, and dissimilarities can be accounted for by differences in analytical methods. The findings presented provide insight into factors that municipalities and student affairs professionals should consider in graduate retention.

Finally, the qualitative findings emphasize that poor town-gown relations not only undermine the student academic experience at Queen's, but also undermine Kingston's potential to utilize the abundant economic resources at its doorstep. Poor town-gown relations have social and economic implications, and for future economic prosperity the city and university administrators must work together to foster better relations. It is, therefore, important to identify strategies and solutions that can be best employed by city and university administrators to realize the economic and social benefits of creating stronger social bonds. Administrators in co-curricular initiatives are well placed to lead such an effort.

\section{Notes}

1. The survey tool used in this study was StudentVoice (see ca.studentvoice.com).

2. This is when untreated observations can be matched more than once with observations in the treatment group; it is a common variant employed by researchers using this method. Caliendo and Kopeinig (2008) assert that matching with replacement is helpful when the propensity score distribution varies between treatment and control groups, and that it can reduce the analytical bias as well as increase the quality of matching.

3. Florida (2004) refers to "tolerance."

\section{References}

Aguiar, L. M., Tomic, P., \& Trumper, R. (2005). Work hard, play hard: Selling Kelowna, BC, as year-round playground. The Canadian Geographer, 49(2), 123-139.

Baxter, L. A. (1991). Content analysis. In B. M. Montgomery \& S. Duck (Eds.), Studying interpersonal interaction (pp. 239-254). New York, NY: The Guilford Press. 
Becker, S. O., \& Caliendo, M. (2007). Sensitivity analysis for average treatment effects. The Stata Journal, 7(1), 71-83.

Becker, S. O., \& Ichino, A. (2002). The estimation of average treatment effects based on propensity scores. The Stata Journal, 2(4), 358-377.

Caliendo, M., \& Kopeinig, S. (2008). Some practical guidance for the implementation of propensity score matching. Journal of Economic Surveys, 22(1), 31-72.

Coffey, A. A., \& Atkinson, P. (1996). Making sense of qualitative data: Complementary research strategies. Thousand Oaks, CA: Sage.

Dehejia, R. H., \& Wahba, S. (2002). Propensity score-matching methods for nonexperimental causal studies. The Review of Economics and Statistics, 84(1), 151-161.

Etzkowitz, H. (2002). Incubation of incubators: Innovation as a triple helix of university-industry-government networks. Science and Public Policy, 29, 115-128.

Florida, R. (2002). The rise of the creative class: And how it's transforming leisure, community and everyday life. New York, NY: Basic Books.

Florida, R. (2004). The rise of the creative class. New York, NY: Basic Books.

Florida, R. (2005). Cities and the creative class. New York, NY: Routledge.

Florida, R. and Cohen, W. M. (1999) Engine or Infrastructure? The University Role in Economic Development in Industrializing Knowledge: University-Industry Linkages in Japan and the United States 589-611 MIT Press

Fox, M. J. (2008, January). Near-campus student housing and the growth of the town and gown movement in Canada. TownGown World. Retrieved from http://www. towngownworld.com/images/town_and_gown_movement_in_canada.pdf

Hubbard, P. (2008). Regulating the social impacts of studentification: A Loughborough case study. Environment and Planning A, 4O(2), 323-341.

Huggins, R., \& Cooke, P. (1997). The economic impact of Cardiff University: Innovation, learning and job generation. GeoJournal, 41(4), 325-337.

Huggins, R., Jones, M., \& Upton, S. (2008). Universities as drivers of knowledgebased regional development: A triple helix analysis of Wales. International Journal of Innovation and Regional Development, 1(1), 24-47.

Knox, P. 2005. Creating ordinary places: Slow cities in a fast world. Journal of Urban Design, 10(1): 1-11.

Li, Q., Racine, S., \& Wooldridge, J. M. (2008). Estimating average treatment effects with continuous and discrete covariates: The case of Swan-Ganz catheterization. The American Economic Review, 98(2), 357-362.

Martin, L. L., Smith, H., \& Phillips, W. (2002). Bridging "town and gown" through innovative university-community partnerships. The Innovation Journal: The Public Sector Innovation Journal, 10(2), 1-16.

Massey, J., \& Gouthro, K. (2011). Community outreach: Assessment and program planning for off-campus students. Assessment Update, 23(1), 6. 
Massey, J., Allen, E., and Shearer, J. P. (2011, Spring) Queen's and Kingston...working creatively together to connect students and local employers. Communiqué (Canadian Association of College and University Student Services).

Massey, J., Chan, Y., Field, S., \& Smith, P. (2011a) The role of career services in facilitating local economic growth - opening doors to students' understanding of local opportunities. The Canadian Journal of Career Development, 1O(1), 562-586.

Montgomery, J. (2005). Beware 'the creative class'. Creativity and wealth creation revisited. Local Economy, 2O(4), 337-343.

Mullin, J. R., Kotval-K, Z., \& Cooper, J. G. (2012). The university and local economic development. Transylvanian Review of Administrative Sciences, 126-136.

Oddie, N., Morton, A. C., Wilson, C., Brett, A., Belina, D., Bolton, S., Lynes, M., Bentley, A., \& Crosby, B. (2009). Residential intensification in Kingston's near university neighbourhoods. School of Urban and Regional Planning, Queen's University. Retrieved from www.queensu.ca/surp/sites/webpublish.queensu.ca.surpwww/files/ files/Project\%20Courses/SURP-824A-2009-Residential\%20Intensification\%20in\%20 Kingston\%20Executive\%20Summary.pdf

Rosenbaum, P. R., \& Rubin, D. B. (1983). The central role of the propensity score in observational studies for casual effects. Biometrika, 7o(1), 41-55.

Russo, A. P., Van den Berg, L., \& Lavanga, M. (2007). Toward a sustainable relationship between city and university: A stakeholder approach. Journal of Planning Education and Research, 27(2), 199-216.

Scott, A. J. (2006). Creative cities: Conceptual issues and policy questions. Journal of Urban Affairs, 28(1), 1-17.

Sharma, A., \& Young, K. (2008). Students, university, and municipal affairs. Ontario Undergraduate Student Alliance. Retrieved from http://www.ousa.ca/wordpress/wpcontent/uploads/2010/o6/Muncipal-Affairs.pdf

Smith, D. (2005). "Studentification": The gentrification factory? In Rowland Atkinson and Gary Bridge (Eds.), Gentrification in a global context: The new urban colonialism (pp. 73-90). London, UK: Routledge.

Universities UK. (2006). "Studentification": A guide to opportunities, challenges and practice. (Catalogue No. 184036127 1). London, UK: Woburn House. Retrieved from http://www.universitiesuk.ac.uk/highereducation/Pages/StudentificationGuide.aspx\#. U34yIl49ZQU

Van Winden, W., Van den Berg, L., \& Pol, P. (2007). European cities in the knowledge economy: towards a typology. Urban Studies, 44(3), 525-549.

Weingarten, H. P., \& Deller, F. (2010). The Benefits of Greater Differentiation of Ontario's University Sector: Final Report. Higher Education Quality Council of Ontario. 


\section{Contact Information}

Jennifer Massey

Department of Geography

Queen's University

ojm@queensu.ca

Jennifer Massey is a doctoral student in the Department of Geography at Queen's University. Her research interests include the geographies of education, student learning, and student engagement, and urban geography.

Sean Field is a PhD candidate in the Department of Geography at Queen's University and an Adjunct Professor in the Queen's School of Business.

Yolande Chan is Associate Vice-Principal (Research), Queen's University and E. Marie Shantz Professor of Management Information Systems, Queen's School of Business. 